\title{
Erratum to: Multiple controls affect arsenite oxidase gene expression in Herminiimonas arsenicoxydans
}

Sandrine Koechler ${ }^{1}$, Jessica Cleiss-Arnold ${ }^{1}$, Caroline Proux ${ }^{2}$, Odile Sismeiro ${ }^{2,1}$, Marie-Agnès Dillies ${ }^{2}$, Florence Goulhen-Chollet ${ }^{1}$, Florence Hommais ${ }^{3}$, Didier Lièvremont ${ }^{1}$, Florence Arsène-Ploetze ${ }^{1}$, Jean-Yves Coppé ${ }^{2}$ and Philippe N Bertin ${ }^{1 *}$

\section{Erratum}

After the publication of our article [1], similarities between lanes 2, 5 and 6 (aoxB-, rpoN- and dnaJ-) and between lanes 3 and 4 (aoxR- and aoxS-) in Fig. 4 were brought to our attention. This error occurred during the compilation of the Western blot images. A corrected version of Fig. 4 has been assembled from the original Western blot experiments and is presented below. This error affects neither the other results nor the conclusions of the article.

\begin{abstract}
Author details
${ }^{1}$ UMR7156 Génétique Moléculaire, Génomique et Microbiologie, CNRS Université de Strasbourg, 28 rue Goethe, 67000 Strasbourg, France. ${ }^{2}$ Plateforme technologique Puces à ADN, Institut Pasteur, 28 rue du Dr. Roux, 75724 Paris cedex 15, France. ${ }^{3}$ UMR5240 Microbiologie, Adaptation et Pathogénie, CNRS Université Lyon 1, Bâtiment André Lwoff, 10 rue Dubois, 69622 Villeurbanne cedex, France.
\end{abstract}

Received: 9 March 2017 Accepted: 9 March 2017

Published online: 28 March 2017

References

1. Koechler S, Cleiss-Arnold J, Proux C, Sismeiro O, Dillies MA, Goulhen-Chollet F, Hommais F, Lièvremont D, Arsène-Ploetze F, Coppée JY, Bertin PN. Multiple controls affect arsenite oxidase gene expression in Herminiimonas arsenicoxydans. BMC Microbiol. 2010;10(1):53.

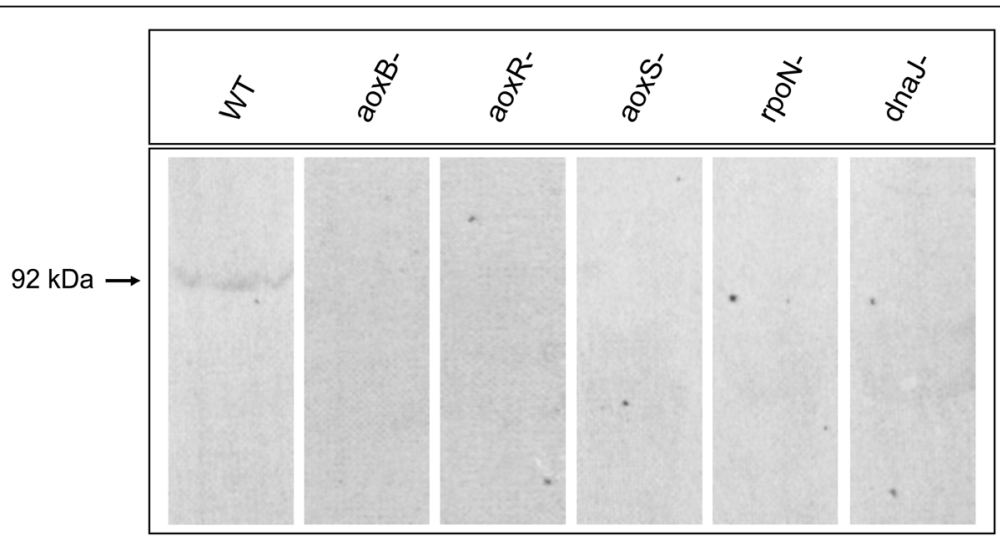

Fig. 4 Immunodetection of AoxB protein in total protein extracts of $H$. arsenicoxydans wild-type and mutant strains

* Correspondence: philippe.bertin@unistra.fr

'UMR7156 Génétique Moléculaire, Génomique et Microbiologie, CNRS

Université de Strasbourg, 28 rue Goethe, 67000 Strasbourg, France 